This is the author's final, peer-reviewed manuscript as accepted for publication. The publisher-formatted version may be available through the publisher's web site or your institution's library.

\title{
The significance of the door in nursing homes: a symbol of control in the domestic sphere
}

Migette L. Kaup

\section{How to cite this manuscript (APA format)}

If you make reference to this version of the manuscript, use the following citation format:

Kaup, Migette L. (2011). The significance of the door in nursing homes: a symbol of control in the domestic sphere. Retrieved from http://krex.ksu.edu

\section{Published Version Information}

Citation: Kaup, Migette L. (2011). The significance of the door in nursing homes: a symbol of control in the domestic sphere. Home Cultures: 8, Pages: 25-42.

Copyright: @ BERG 2011

Digital Object Identifier (DOI): not yet published

Publisher's Link: http://www.ingentaconnect.com/content/berg/hcu 
The Significance of the Door in Nursing Homes: A Symbol of Control in the Domestic Sphere

\section{Author:}

Migette L. Kaup, IDEC, IIDA

221 Justin Hall

Department of ATID - College of Human Ecology

Kansas State University

Manhattan, KS 66506

3 Sentence Bio - Migette L. Kaup, IDEC, IIDA: Migette Kaup is an Associate Professor at Kansas State University and an Interior Designer specializing in gerontological and universal design. She holds a Bachelor of Science in Interior Design and Masters of Architecture in Environment \& Behavior and Place Studies with an emphasis in Gerontology from Kansas State University. Her professional practice includes over 9 years in architectural firms as well as 7 years in private consulting to long-term care providers on design planning. 


\section{The Significance of the Door in Nursing Homes: A Symbol of Control in the Domestic Sphere}

The door, as an architectural signal, is universally identifiable and metaphorically powerful. One can state that there is an "open-door policy,” signifying receptiveness to communication between individuals and groups. Or, counter to this is the position, "she slammed-the-door on the idea," signifying that someone has been closed out or cut off. The semiotics of the images may be culturally bound, yet still implies access to and control over a relationship. These meanings can also be enacted through space, and "by analyzing the process by which these everyday meanings are reified and regimented in architectural form, we are better able to see how power shapes discourse and social practice (Landes 2003, 36).”

The door is a significant component of almost every place type. This singular feature signifies control over space and access to the inner world of someone's life. It is incorporated to regulate access, delineate territory, and to protect privacy. The door is one of the strongest elements that communicate boundaries. As noted by Wolfe, "boundaries are the stuff of sociology, and in modern societies no boundary seems quite as important, yet quite as porous and ambiguous, as the one between public and private ${ }^{1}$." The public/ private distinction can be analyzed as a communicative phenomenon that involves a product of semiotic processes (Gal 2002, 77). This paper will explore how the public/ private contradictions can be enacted in the space of the nursing home through the use of architectural features that signal transition and passage, most specifically the door. The case study explored here is Meadowlark Hills, a nursing home in the Midwestern United States that has transformed their institutional nursing home into 
a "household." The use and placement of doors and doorways in a single nursing home environment before and after remodeling will be the unit of analysis.

The discussion and conclusions are based on the concepts of control and hierarchy that are expressed through this architectural feature. The interpretations of meaning and consequence of these features are based on participant observations made during a 24-hour stay in the facility ${ }^{2}$, as well as a culmination of fieldwork and participant observation that spans over ten years of interactions with the nursing home staff, residents and their families as well as administrators at Meadowlark Hills both before and after changes were made to the building. These interpretations are reified through documented case studies of other nursing homes (in the US), public policy ${ }^{3}$ and social advocacy that have described the prevailing conditions of nursing homes $^{4}$ and identified the built environment as a mechanism for restoring control to the residents who live within these settings (e.g. Noell 1995-96; Gonyea 2005).

The premise is that patterns of public and private space have been taken for granted in the nursing home, to the degree that some solutions to the spatial configuration and locations of doors are not longer questioned. There continues to be a missing link to creating an environment that truly begins to embody the essence of home, and this gap requires us to investigate more deeply the fundamental associations about the doors within environments that shape our perceptions of what we call "home," to understand how the spaces of nursing homes are enacted and formed to support more domestic attitudes and behaviors. By exploring the role of the door, we can witness a form of spatial power that suppresses those who reside within.

Home is a significant "place” in our lives. The literature often emphasizes the attachment that we have to our homes (e.g. Moore et al. 1974; Tognoli 1987; Dovey 1993; Lawrence 1987; Norberg-Schulz 1985; Kumar 1997). In the case of the door, there are meanings that are 
internalized by its placement and use within space. Front doors on homes are important landmarks for visitors. "The lavish attention that has been spent on entry places in all forms of architecture attests to the importance of the territorial distinction between inside and outside (Moore et al. 1974, 214).” The domains of inside and outside do not necessary require outside being "outdoors" - rather it could be conceived to be a designation of "included and excluded" belonging or stranger/ visitor. It reflects the actions of retreat and protections and control, enacted through the processes of opening and closing of doors. "It is assumed that the home is where privacy is needed most, and the more intimate areas of the house are often located behind a number of barriers, such as doors (Tognoli 1987, 660).” Within our homes, “each door implies a path, requires an action, and either shuts away a segment of domestic life or opens it to view, to hearing, and to smell, and sometimes to the outdoors ${ }^{5}$ (Moore et al. 1974, 215).” We use doors to screen some forms of social behavior (Wolfe 1997, 182), not just from the public sphere but also within the dwelling among family members and invited guests. These architecturally defined features signal a distinction between public and private that can be reproduced repeatedly by projecting it onto narrower contexts and how a single pattern recurs inside itself often with multiple nestings” (Gal 2002, 81-82). Each time we step further into a home we interact with the space in a tacit manner, adjusting our behaviors to respond to the context of social exchange. We gather in the living room, we pass each other in the hallway; we shut the door to the bathroom to shield personal activities.

We use the public/ private distinction to develop a conceptual framework for demarcating important boundaries around the "private" world of intimacy and family and the "public" world of sociability and work (Weintraub 1997, 2). The nursing home becomes the world of both; world of work and world of residence; neither distinctly private nor public yet simultaneously 
private and public. Although not often considered a residential building type, nursing homes are indeed a domestic space. Nursing homes are often the last place of residence for elders who will spend many years within these settings (Spillman and Lubitz 2002). The nursing home environment in the United States is an example of space that reflects the structures of the current social systems through spatial design that enable or constrain the capacity of those within the setting (Dovey 1999). Most long-term care administrators would claim that their facilities no longer reflect Goffman's total institution of late 1950's and early 1960's'. They would say the regulatory oversight provides for residents' rights and these places are safe and humane. While policies may have advanced the practices of care, the architecture of these institutions has not changed significantly since the 1950 's. Building standards were and continue to be patterned after other highly controlled and regulated settings. This has the effect of nursing homes resembling institutions rather than a domestic space both in form as well as experience (Schwartz 1996; Cohen-Mansfield et al. 1995, 419; Aranyi and Goldman 1980; Koncelik 1976). As we look at the spaces of the nursing home, analyze its formal structure and its materiality, what does it say about the lives lived inside?

Nursing homes become a place of residence for many older adults in their later years ${ }^{7}$, and they are significant to the lives of their occupants as well. In America, more than half of adults, younger than age 90 , who enter a nursing home will spend a year or more there, but at least 20\% will spend 5 years or more (Spillman and Lubitz 2002, 970). Unlike the "homes,” they leave behind, however, these places reflect a change in the control the elder will have over their spaces. This lack of control is exhibited through the incongruence of how doors are enacted in the setting. This is not to suggest that nursing homes do not have doors, rather that these doors are mechanisms of control that demonstrate the social behaviors of the collective institution. 
In the sections that follow two alternative forms of the institutionalized skilled care setting will be described. The first represents the state of the most common form of nursing home, an institution that has been pattered after a hospital; the second represents an emerging place-type in long-term care called "a household”, patterned after the domestic home. The divergent spatial experiences of these settings will be expressed through the role of the doors and the supporting transitional features that are architecturally determined and will compare and contrast the dramatic changes that can occur in the ideological communication of these domains. Their use, their language, and therefore their meaning within the spaces suggested through the patterns of behaviors they support.

\section{Institutional Nursing Home Doors as a Contradiction to Domestic Privacy and Control}

Home is a universally identifiable term with a range of concepts so the discussion of "homelike" should begin by defining what is implied by the term and by describing its limits and context in this framework. Literature on the theoretical perspectives on the meanings of home includes both those phenomenological and ideological factors associated with human experience and the built form (e.g. Dovey 1993; Lawrence 1987; Norberg-Schulz 1985; Kumar 1997). Each of these premises, however, acknowledges the presence and distinctions between public and private domains and the transitions and divisions between these domains that influence behaviors (or access to and) within the spaces. What happens, however, when the institution of nursing home becomes our home? Is the institution a public place or a private space, or both? As will be described through the story of Meadowlark Hills, those who reside permanently within these types of settings may relinquish their ability to retreat from public view, creating confluence of 
power, autonomy and control over their lives. While the meanings of public and private are contextually sensitive and shifting, there is one invariable aspect of the distinction: "the open and revealed versus the hidden or withdrawn; and the collective versus the individual (Landes 2003, 33-34).”

Unlike the analysis of public domain and the world of social labor that has embedded itself into the private sphere of the domestic setting of women who work from home (Gal 2002, 84), nursing homes present an opposite phenomena of the private world of intimate care that has been embedded into the public domain of the social workforce and the healthcare "business." When care becomes a pubic act, these worlds can collide. "The values, feelings, and interactions that make up the relational essence of care in the private sphere are sometimes devalued, discouraged and even forbidden in the public world. Care givers and the people they care for are pressured by norms, rules and policies of the public world to make care conform to the image of work that predominates in the public world (Stone 2000, 90).” The architecture of Meadowlark Hill's nursing home and the patterns of human and organizational behavior provided ample evidence where the balance of power resided.

Meadowlark Hills skilled nursing facility was originally constructed in the early 1980s. The resident population includes frail elders who require 24-hour care services. ${ }^{8}$ In its original design, spaces in the Meadowlark Hills nursing home were conceived based on the locus of power that revolved around those who were charged to care for elders. Visual access for nurses was achieved architecturally by placing a large nurses' station at the junction of all hallways (See Figure 1). This was a common response to regulations that stipulated the requirement to be able to monitor every door from a single vantage point. In this layout, privacy domains once held sacred in the places we call "home" are conflicted as they are juxtaposed with public spaces 
designed to observe, control and circulate movement front point to point. The doors continue to be observed and controlled by the "wardens" of the spaces not the "tenants." The right to deny entrance, shut the door, lock the door, open the door are actions that are themselves highly controlled. It begins at the entrance to the nursing home that is open to all. As depicted in the original floor plan of Meadowlark Hills (Figure 1), the major entry point at the front of the building leads directly to bedrooms. What is not blatantly evident from a two-dimension representation is the experience of the space from a resident's perspective. There is a loss of control that results from having the front door to your home accessible to all in the community. Visitors freely come in and out of this opening in the building, unlike the openings in other houses in community. The volume of strangers that pass through the entrance, moving swiftly by elders parked in wheelchairs (usually around the nurses’ station) past their bedroom doors reflect the total lack of power the "residents" have over the access to "their home."

As we move further into this original layout (Figure 1), the use of doors continues to be controlled by others, both in their physical structure, but also in the rules that apply to their use. By US building regulation for skilled nursing facilities, door openings to resident rooms must be 44" in width. If a single door is used to fill this space, it will be heavier and more cumbersome to operate especially for those of frail statures. A common consequence is that the width of the door defines the passage width into the room. The position of the doors impedes use and access by someone in a wheelchair or dependent on a walker (see Figure 2). If a door happens to be shut, a resident may in essence be "trapped" inside a room until someone comes for them. The door to the resident room is there to protect the privacy of those who reside within the institution, but since the door may not be manageable by the resident it is left to stand open. All too often visitors can look through open doors and see elders struggling with intimate and personal 
activities. Rising from a toilet, dressing, disrobing, or simply having an intimate encounter with another, become activities that are not concealed from open view. The architecture exerts control over the resident, designed around the assumption that residents' autonomy and privacy is not a criterion that must be addressed through built form.

The door to the resident's room should be the primary threshold to an identifiable territory, under the relative control of the resident. Yet, in some cases nursing homes residents are discouraged from shutting their doors or keeping their doors closed. These actions are only permitted by the staff who claimed they must be able to observe the resident at all times, which as a consequence means they are also in view of anyone else that walks past as well. This is expressed out of a concern for the residents' well-being, “what if you fall out of bed?” But the residents' well-being of a good night's sleep without the intrusion of the corridor lights that are on all night is not seen as important, nor is it seen as a protection of their right to this sort of privacy. In our homes, however, we don't sleep on display.

Few activities in the nursing home are private, as they would be in our own homes. The call lights that flash above the doors and audible buzzing down the halls communicates to all the personal care, such as toileting, needed by individuals. And, the persistence of the light is a constant reminder of a compromised stated. The more caring staff shut the door for various procedures, but regulations are required to mandate the appropriate actions in order to protect privacy (CMS 2009). Intimacy and the personal displays of affection are central to our spaces within our homes (Lustbader 2000). In this nursing home, however, there are few spaces for truly private exchange - with privacy comes lack of supervision and lack of supervision means lack of control. Affection and intimate contact for elders in the nursing home who fall in love and want to welcome each other into their beds are limited by doors to bedrooms that don't close. This 
forces a denial of emotions because residents are bound to the space and its demand for public displays of all interactions (Hajjar and Hosam 2003, 576).

The location of the bathing room door in this nursing home is another contradiction of the expected private domains within the domestic sphere. The entrance to the bathing room is located off a public hallway. If a resident is wheeled to the shower room it might be done draped in a barber-shop like tarp or maybe their robe. While they are clothed to conceal their nakedness, their route to the shower room takes them through the public spaces maybe even past the front door announcing their "bathing" activity. In our homes such displays of personal activities are shielded from guests. Once inside, the door may be closed, but other staff may continue to open the door indiscriminately to access supplies or soiled linen bins that are stored within this space. The resident is told not to worry; however, it's only another staff person.

If residents are not allowed to control the doors within their environments, they are not allowed a "reality" that is afforded to others who have a private home (Goffman 1959, 24) rather they are always on stage to be viewed by the public. "Indeed, the door may be the most important of all of Goffman’s images (Wolfe 1997, 182).” Without privacy we relinquish the nature of mutual dependencies that form the foundations of friendship, love, trust (Silver 1997, 43). When the rules (structures) of the institution will not permit a resident to close the door, they cannot close-out unwanted intrusion, even if it is just a passing glace of a stranger moving down the hall. Their only retreat becomes the retreat inward (Lustbader 1999), they circumvent the power of those whose care dominates their lives by their complacency; counting the days until their bodies release their minds from the physical (and structural) constraints the nursing home world has placed upon them (Fuerderer 2008; Seaver 1994, 11). 


\section{The Skilled Care "Household:" Using the Door as a Symbol of "Home"}

The recognition of these multiple violation of the private world for residents, and the lack of control that results, has led to the emergence and evolution of a new place type within these skilled care settings. Emerging household models and small house designs in long term care are being patterned after domestics spaces and have been receiving increasing evaluative attention (e.g. Grant and Norton 2003; Shields and Norton 2006; Rabig et al. 2006). The "household" is being introduced through either a reconfiguration of existing space, or even an abandonment of the old structure and replacement with a new stand-alone setting. The re-conceptualizing of the nursing home into a new place type returns us to the theoretical premises of home and domesticity. Inhabitants are perceived as having control over their setting. "Elements important in maintaining this congruence include the nature of the group, communication and privacy needs, symbols of status, the nature of activity systems and the social organization (Tognoli 1987, 665)." Once more a prominent feature of the house is the door, and crossing this threshold once again becomes a transition from public to private, from social world to the sanctity of home.

The expression of change through built form signals a visible shift in social ideals. Social and cultural change can result in new building types, but more commonly are addressed by modifications to existing building forms (King 1980, 29), and many facilities ${ }^{9}$ are indeed modifying space within an existing facility. Meadowlark Hills has been an example of a nursing home that has experienced a significant change as they remodeled their traditional T-shaped institution (Figure 1) into three distinct households (Figure 3). As shown Figure No. 4, each of the new households is provided a unique residential front door with a doorbell that is used to request entrance to the semi-public social space within the household. Architectural features 
now provide the full continuum of public to private spaces starting with a transitional space created at the front porch and then continuing past the front door.

The Meadowlark Hills households attempt to recapture the privacy and the distinctions and gradients between public worlds and private spaces. The door is now returned to its origin of control and plays a part in the full continuum of public to private spaces starting with a transitional space created at the front porch and then continuing past the front door. The household creates different boundaries increasing the residents' ability to identify with a family unit. Access to each of the households is provided through a unique residential front door with a doorbell that is used to request entrance to the semi-public social space within the household. The built features of the environment become the visible vehicles for the manifestation of the order of the dwelling, and the resulting behaviors become affected through these built forms.

The reduced scale along with dedicating consistent staff to the household has created a collective group of people who now identify with a specific territory. The domains of public to private are more clearly defined in the household and the doors are allowed to convey the control residents have over their space. Therefore, the nursing home once again becomes a series of “nested spaces" 10 with public and private zones within a public institution. Like the "private" home that has a public side for guests within the private sphere for the intimate activities of the family, the "public" nursing home has a private side for the residents within the public sphere. Once a visitor is invited into these homes, they enter into an open social area, or a public space nested within the household. Doors to bedrooms and bathing areas are now located beyond the living room, down corridors that reflects a similar arrangement to a vernacular dwelling. These transition spaces between social areas and more private spaces are also architecturally defined. Private spaces for residents and their "invited” guests are along this transitional space. Residents 
can go into bathing rooms or other private and semi-private spaces without having to cross over semi-public or public domains, thus increasing privacy and dignity in a way that more closely models traditional residential patterns. Spatial sequence and architectural expressions are now used to support privacy and territoriality (Rabig et al. 2006; Shields and Norton, 2006). Circulation patterns through these households now follow a residential hierarchy of space. The community moves in and out of some of these spaces rather freely, while respecting the boundaries of the established domestic spaces that are now more clearly communicated through built form. The roles of public and private space are constantly intermingled in the everyday experiences ${ }^{11}$ but in a manner that does not violate the domesticity of the household.

These nested relationships and parallel behaviors (expressive actions of control and contact) are difficult to notice in the instant they occur, but may be the essence of the spatial experiences. The influence of the presence of the door was noted by one administrator when reflecting on a comment by a family member who had come to visit her mother for the first time after the remodel of their nursing home into a "household." The presence of the new front door gave the signal that entry was not "automatic" and she contacted the administrator to ask how she was to get in to see her mother. When he suggested that she ring the doorbell and someone would come to the door she was at first put off, "You mean I have to ring the doorbell to get into see my own mother?" she asked. The administrator responded, “It's between you and your mother how you come and visit her in her own house.” This single response exemplifies the culture that has been shaped by the institution we call "nursing home." When family moves into a care setting, it is usually associated with leaving their homes. The idea that her mother was "residing" in a place that had a meaning was so foreign to the family member that at first the concept of a front door to the house was not associated with the level of housing and care she 
had been accustomed to visiting. In the new households, family members are often welcome to “come-on-in” just as they might if they were visiting a close family member. Other 'visitors,' including staff who do not work on the household, ring the bell. Staff and residents who are in the social spaces of the household will go to the door or even just signal to those waiting at the door that they should enter.

Institutions like Meadowlark Hills that are evolving both their settings and their behavioral expectations are experiencing how these new landscapes can be expressed in the role of the door, it's placement in space, the rules that guide its use. The conscious expression may be to ignore or diminish gradients of the public/private domains, occupants may only be able to consciously articulate the distinctions of private versus public space when in reality their behaviors are actualized along a continuous reality (Gal 2002, 91), but the reintroduction of the visual cues provided through materiality and architectural forms is contributing to the subjective experiences of staff, residents and their families (Silverstein and Jacobson 1985). Residents in the Meadowlark Hills households are in control of the use of their doors; these doors are designed to be usable by frail elders and may be shut at anytime. The display of intimate activities (such as on open door into a bathing room) would not considered appropriate in the household. The open door is no longer considered a function for "protective observation." The staff who work in the household settings understand that they are to knock on the door first and be invited into the space by the resident. New spatial arrangements in the households permit the location of entrances to bathing rooms to be more proximate to the private zones of the house, and residents do not have to pass through open social areas on their way to this location. Intruding on this space is now seen as a violation of resident privacy, staff can wait. The fractal 
nature of public and private that come into play when considering the separate spheres of home and nursing home are now allowed to be reconsidered.

\section{Towards A New Domesticity in Nursing Homes}

The landscape of our nursing homes is a traceable artifact (Schein 2006, 3) that provides an empirical history about societal ideas about what it means to grow old in America ${ }^{12}$. But does our past represent our future when we are capable of reshaping nursing home spaces to reflect those qualities of domestic life that we hold dear? The doctrine of 'separate spheres' fosters an assumption that the social world is organized around contrasting and incompatible moral principles that are conventionally linked to either public or private, but there are no real stable boundaries between public and private either in our homes or in the nursing homes we design and occupy (Wolfe 1997, 191-192; Gal 2002, 78). Changes to the distinctions between public and private can begin to emerge through incremental modifications of space (Hayden 1995, 15). Symbols of the culture and rituals of space may become critical in the initial stages of change to reinforce the needed association with desired behaviors of domestic space (Siegel 1970, 26). These can include rituals that allow for reinforcement of values and behaviors that are part of the home-like pattern. Knocking on doors to request entry, celebrating events, preparation of foods together as a household can all be examples of behaviors that add meaning to the experience of place. In conjunction with the appropriate physical settings and architectural cues, rules and rituals help create an environmental milieu that prevents the user from having to totally restructure the cognitive schemata (Rapoport 1980).

This new place type called a nursing home "household” reflects deeper differences in both theoretical and ideological commitments, in society’s assumptions about what long-term 
care should be in America. The intent for designers should be to put into place the structures that embody the patterns of behavior reflective of the complex combinations in the ordinary routines of everyday family life. Like our homes, the nursing home should provide for a series of "nested" spaces that that allow for the interspatial aspects to be more fully experienced. The proper function of space will require appropriate behavior and the adoption of social and cultural rules which are assumed in their design (King 1980, 29; Schultz and Heckhausen 1999). We are capable of setting a stage that permits the recreating and recurring patterns within multiple layers of the setting. Susan Gal $(2002,85)$ notes "redefinitions that create public inside a private or a private inside a public can be momentary and ephemeral, depending on the participants. Or, they can be made lasting and coercive, fixing and forcing such distinctions, binding social actors through arrangements such as legal regulation and other forms of ritualization and institutionalization.” As institutions that provide both housing and care, nursing homes can rise to meet these challenges if we begin to acknowledge the opportunities that can be provided through built forms. The simplicity of features such as the door conveys powerful messages. These symbols and material artifacts can provide visible manifestations for re-conceptualizing what we mean when we say nursing "home" and draw our minds back to the values central in our everyday lives. 


\section{Notes}

1. For further reading, see Public and Private in Thought and Practice: Perspectives on a Grand Dichotomy. (Chicago, IL: The University of Chicago Press, 1997), 187.

2. I moved into Meadowlark Hills and resided there for a period of over 24 hours to experience the setting from a difference perspective. I spent the entire time moving through the space in a wheelchair, participating in the daily activities alongside other residents. I slept in a shared room and was "bathed” by an attendant. My observations and experiences have been documented and published. For a more complete accounting on this see, “Personal Experience Clues Designers to need for Culture Change,” Culture Change Now 3 (2005): 22.

3. Since the passage of the Omnibus Budget Reconciliation Act (OBRA) 1987, increased attention has been given to improving the quality of America's nursing homes. While most concern has addressed the safety and quality of medical care delivered, there is a growing acknowledgement that the quality of life experienced within in these institutions should be given equal attention (Kane 2005; Lustbader 2000; Fagan 2003; Vladeck 2003).

4. These descriptions can represent hundreds of nursing homes across the American landscape. Nursing home institutions have been homogenized through the regulatory structure to the degree that they have generic features.

5. It may also represent actions and spaces that connect us to the broader community, such as picking up our mail curb-side or sitting on the front porch watching neighbors pass by (Belgum 1993). 
6. See Asylums: Essays on the Social Situation of Mental Patients and Other Inmates. Garden City, NY: Doubleday, 1961.

7. Other forms of senior housing such as independent living assisted living as well as specialized dementia care facilities have been quicker to base their design principles around domestic spaces. For further reading see Howell, Sandra C. 1980. Design for Aging: Patterns of Use. Cambridge, MA: MIT Press, Brummett, William. C1997. The Essence of Home: Design Solutions for Assisted Living Housing. New York: Van Nostrand Reinhold, and Cohen, Uriel and Weisman, Gerald. 1991. Holding onto Home.

8. Residents who had dementia based conditions were care for in a dedicated portion of the facility at the end of one of the long hallways prior to the remodel. After the remodel these special care memory support services were located in another dedicated part of the expanded campus to encompass the necessary safety features.

9. Another significant example is the development of new stand-alone "households" that are beginning to dot the urban landscape across the country. The Green House ${ }^{\circledR}$ model is a central example of re-conceptualizing the nursing home by adopting the terminology of domesticity and designing physical space around these descriptors (Rabig, et al. 2006, 535). Founders of the Green House ${ }^{\circledR}$ acknowledged that it was through the household environment that behaviors became internalized and demonstrated. The role of the environment allows the organization to focus on doing the work in congruence with their stated values, creating a "home" for those who live there (Thomas 1995).

10. Susan Gal $(2002,81)$ described these "nestings" as the distinction between public and private that can be reproduced repeatedly by projecting it onto narrower contexts or broader ones and further categorized into private and public parts. 
11. Susan Gal notes that "since the emergence of the doctrine of separate spheres, there has been an assumption that the social world is organized around contrasting and incompatible moral principles that are conventionally linked to either public or private. See, "A Semiotics of the Public/ Private Distinction.” differences; A Journal of Feminist Cultural Studies 13.1 (2002), 78.

12. In their original conception, these institutions were not designed around the principles of home, and even today, not much has fundamentally changed in their design (For further reading, see Brown-Wilson \& Baldwin 1995-96; Noell 1995-96; Pynoos \& Liebig 1995; Hiatt 1992; Hiatt 1991). 


\section{Sources for Bibliography and Footnotes - Chicago}

Action Pact. 2005. "Personal Experience Clues Designers to Need for Culture Change.” Culture Change Now 3: 22-24.

Altman, Irwin. 1977. "Privacy Regulation: Culturally Universal or Culturally Specific?” Journal of Social Issues, 33 (1977):66-83.

Aranyi, Laszlo and Larry L. Goldman. 1980. Design of Long-Term Care Facilities. New York: Van Nostrand Reinhold.

Belgum, Kirsten. 1993. “Representation and Respite: The Interior and Women’s Domestic Work in the Nineteenth Century.” Center, 8: 33-43.

Brown-Wilson, Keren and Baldwin, Connie J. 1995-96. “Are Nursing Homes Dinosaurs?” Generations; Journal of the American Society on Aging 19(4): 69-72.

Brummett, William. c1997. The Essence of Home: Design Solutions for Assisted Living Housing. New York: Van Nostrand Reinhold.

Center for Medicare \& Medicaid Services (April 10, 2009). State Operations Manual: Appendix P - Survey Protocols for Long Term Care Facilities - Part I, (Rev. 41). Baltimore, MD: Author.

Cohen, Uriel and Gerald D. Weisman. 1991. Holding onto Home: Designing Environments for People with Dementia. Baltimore, MD: John Hopkins University Press.

Cohen-Mansfield, Jiska, Werner, Perla, Weinfield, Michael, Braun, Judith, Kraft, Gladys, Berber, Barbara, and Willens, Steve. 1995. “Autonomy for Nursing Home Residents: The Role of Regulations.” Behavioral Sciences and the Law 13: 415-423. 
De Certeau, Michel. 2002. "General Introduction to the Practices of Everyday life, The Everyday Life Reader, edited by Ben Highmore, 63-75. New York: Routledge.

Dovey, Kim. 1993.“Dwelling, Archetype and Ideology.” Center 8: 9-21.

Dovey, Kim. 1999. Framing Places: Mediating Power in Built Form. New York: Routledge.

Fagan, Rose Marie. 2003. "Pioneer Network: Changing the Culture of Aging in America.” Journal of Social Work in Long-term Care 2(1/2): 125 - 140.

Fuerderer, Yvette. “A Day in Her Life.” agedcarecrisis.com, (September 12, 2008). http://www.agedcarecrisis.com/nursinghomes/a-day-in-her-life (accessed May 8, 2009).

Gal, Susan. 2002. “A Semiotics of the Public/ Private Distinction.” differences; A Journal of Feminist Cultural Studies 13.1: 77-95.

Goffman, Erving. 1961. Asylums: Essays on the Social Situation of Mental Patients and Other Inmates. Garden City, NY: Doubleday.

Goffman, Erving. 1959 Presentation of Self in Everyday Life. Garden City, NY: Doubleday. Gonyea, Judith G. 2005. “The Oldest Old and a Long Lived Society.” In The New Politics of Old Age Policy edited by Robert Hudson, 157-181. Baltimore: John Hopkins University Press.

Grant, Leslie and Norton, Lavrene. “A Stage Model of Culture Change in Nursing Facilities.” (presentation at symposium: Culture change II: Theory and practice, vision and reality, the $56^{\text {th }}$ Scientific Meeting of the Gerontological Society of America. San Diego, November 2003).

Hajjar, Ramzi R. and Kamel, Hosam, K (2003) “Sex and the Nursing Home.” Clinical Geriatric Medicine (19): 575-586. 
Hayden, Dolores. 1995. The Power of Place: Urban Landscapes as Public History. Cambridge, MA: MIT Press.

Hiatt, Lorraine G. 1992. “Long-term Care: Future Possibilities.” Journal of Health Care Design Proceeding from the Symposium on Health Care Design 4: 55-64.

Hiatt, Lorraine. G. 1991. Nursing Home Renovation Designed for Reform. Stoneham, MA: Butterworth-Heinemann.

Howell, Sandra C. 1980. Design for Aging: Patterns of Use. Cambridge, MA: MIT Press.

Kane, Robert L. 2005. “Changing the Face of Long-Term Care.” Journal of Aging and Social Policy 17(4): 1-18.

King, Anthony. 1990. “Architecture, Capital and the Globalization of Culture.” Theory, Culture \& Society (7): 397-411.

Koncelik, Joseph A. c1976. Designing the Open Nursing Home. Stroudsburg, PA: Dowden, Hutchinson \& Ross.

Kumar, Krishan. 1997. "Home: The Promise and Predicament of Private Life at the End of the $20^{\text {th }}$ Century.” In Public and Private in Thought and Practice: Perspectives on a Grand Dichotomy, edited by Jeff Weintraub and Krishan Kumar, 204-236. Chicago, IL: The University of Chicago Press.

Landes, Joan B. Summer 2003. “Further Thoughts on the Public/ Private Distinction.” Journal of Women's History 14(2): 28-39

Lawrence, Roderick. 1987. Housing, Dwellings, and Home: Design Theory, Research, and Practice. New York: John Wiley \& Sons. 
Lustbader, Wendy. 2000. “The Pioneer Challenge: A Radical Change in the Culture of Nursing Homes.” In Qualities of Caring: Impact on Quality of Life, edited by Linda Noelker and Zev Harel, 185-203. Rochester, New York: Springer.

Lustbader, Wendy. Winter 1999. “Thoughts on the Meaning of Frailty.” Generations 23(4): 2124

Moore, Charles, Allen, Gerald. \& Lyndon, Donlyn. 1974. The Place of Houses, 207-220. New York: Holt, Rinehart \& Winston.

Noell, Eunice. Winter 1995-96. “Design in Nursing Homes: Environments as a Silent Partner in Care Giving. Generations; Journal of the American Society on Aging, 29(4): 14-19.

Norberg-Schulz, Christian. 1985. The Concept of Dwelling: On the Way to Figurative Architecture. New York: Rizzoli International Publications, Inc.

Pynoos, Jon and Phoebe S. Liebig. 1995. Housing Frail Elders; International Policies, Perspectives, and Prospects. Baltimore, MD: The John Hopkins University Press.

Rabig, Judith, Thomas, William, Kane, Rosalie A., Cutler, Lois J., \& McAlilly, Steve 2006. "Radical Redesign of Nursing Homes: Applying the Green House Concept in Tupelo, Mississippi. The Gerontologist, 46(4): 533-539

Rapoport, Amos.1982. Environmental Meaning. Tucson, AZ: The University of Arizona Press.

Schein, Richard H. 2006. Landscape and Race in the United States. New York: Routledge.

Schulz, Richard \& Heckhausen, Jutta. 1999. “Aging, Culture and Control: Setting a New Research Agenda. Journal of Gerontology: Psychological Sciences, 54B(3): P139-P145. 
Schwartz, Benyamin. 1996. Nursing Home Design: Consequences of Employing the Medical Model. New York: Garland Publishing.

Seaver, Anna Mae Halgrim. 1994. "My World Now: Life in a Nursing home, from the Inside.” Newsweek, June 27.

Shields, Stephen \& Norton, Lavrene. 2006. In Pursuit of the Sunbeam: A Practical Guide to Transformation from Institution to Household. United States of America: Action Pact Press.

Siegel, Bernard. J. 1970, July. "Defensive Structuring and Environmental Stress.” The American Journal of Sociology 76(1): 11-32.

Silver, Allan. 1997. “Two Different Sorts of Commerce” - Friendship and Strangership in Civil Society.” In Public and Private in Thought and Practice: Perspectives on a Grand Dichotomy, edited by Jeff Weintraub and Krishan Kumar, 43-74. Chicago, IL: The University of Chicago Press.

Silverstein, Murray and Max Jacobson. 1985. "Restructuring the Hidden Program: Toward an Architecture of Social Change. In Programming and the Built Environment, edited by Wolfgang Preiser, 149-164. New York: Van Nostrand.

Spillman, Brenda. C. \& Lubitz, James. 2002. "New Estimates of Lifetime Nursing Home Use: Have Patterns of Use Changed?” Medical Care, 40(10): 965-975.

Stone, Deborah. 2000. “Caring by the Book.” In Care Work: Gender, Labor, and Welfare States, edited by Madonna Harrington Meyer, 89-111. New York: Routledge. 
Thomas, William H. c1995. “Long-term Care Design: Building Homeness into Existing Longterm Care Facilities.” In Journal of Health Care Design Vol. 10. Symposia on Health Care Design, edited by S. O. Marberry, 57-61. New York: Van Nostrand Reinhold.

Tognoli, Jerome. 1987. “Residential Environments.” In Handbook of Environmental Psychology edited by Daniel Stokols \& Irwin Altman, 655-690. New York: Wiley.

Vladeck, Bruce. C. 2003.“Unloving Care Revisited: The Persistence of Culture. In Culture Change in Long-Term Care edited by Audrey S. Weiner \& Judah L. Ronch, 1-10. New York: Haworth Social Work Practice Press.

Weintraub, Jeff. 1997. “The Theory and politics of the Public/Private Distinction.” In Public and Private in Thought and Practice: Perspectives on a Grand Dichotomy, edited by Jeff Weintraub and Krishan Kumar, 1-42. Chicago, IL: The University of Chicago Press.

Wolfe, Alan. 1997. "Public and Private in Theory and Practice: Some Implications of an Uncertain Boundary.” In Public and Private in Thought and Practice: Perspectives on a Grand Dichotomy, edited by Jeff Weintraub and Krishan Kumar, 182-203. Chicago, IL: The University of Chicago Press. 


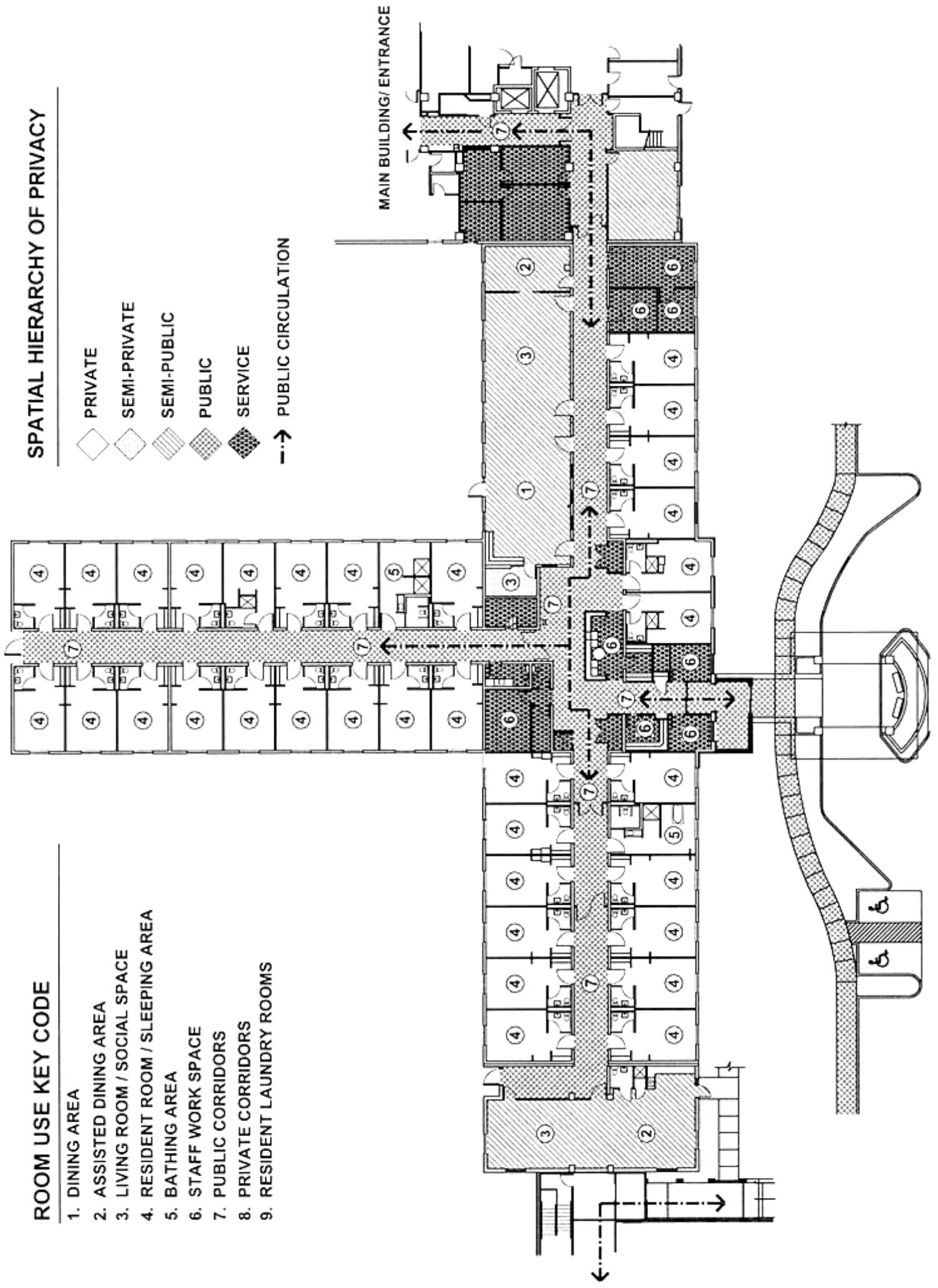

Figure No. 1 - Meadowlark Hills Nursing Home Plan before Remodel:

Common Institutional Layout 


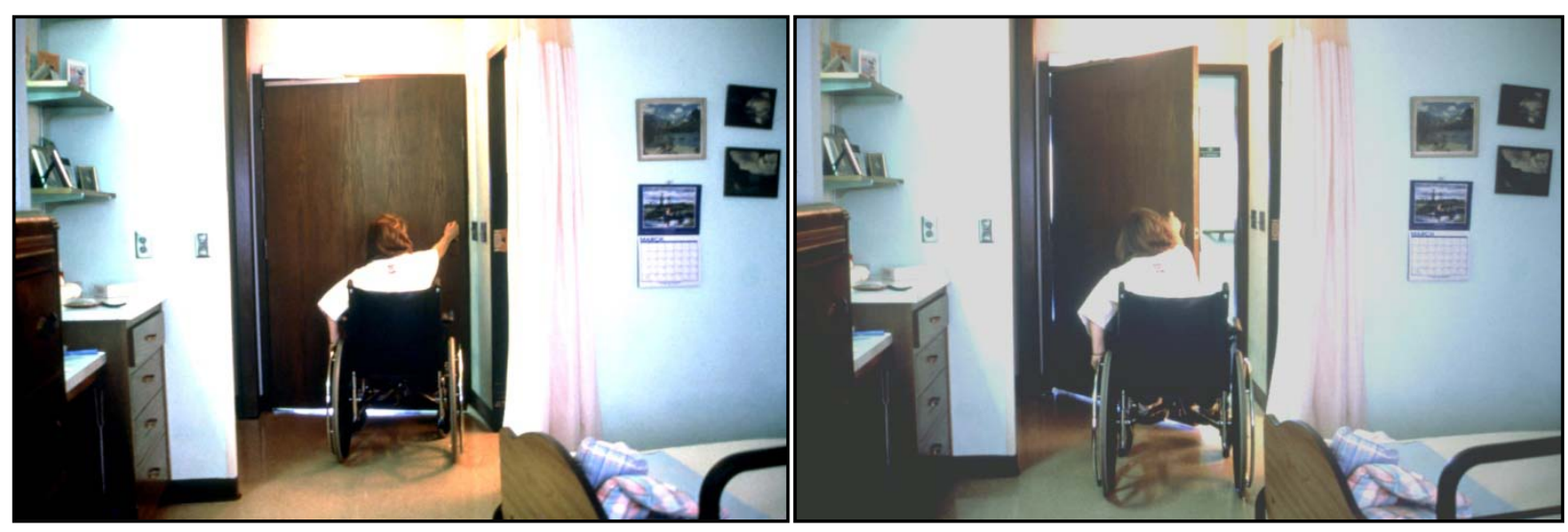

Figure No. 2 - Photos of author trying to negotiate a door in a resident room. 


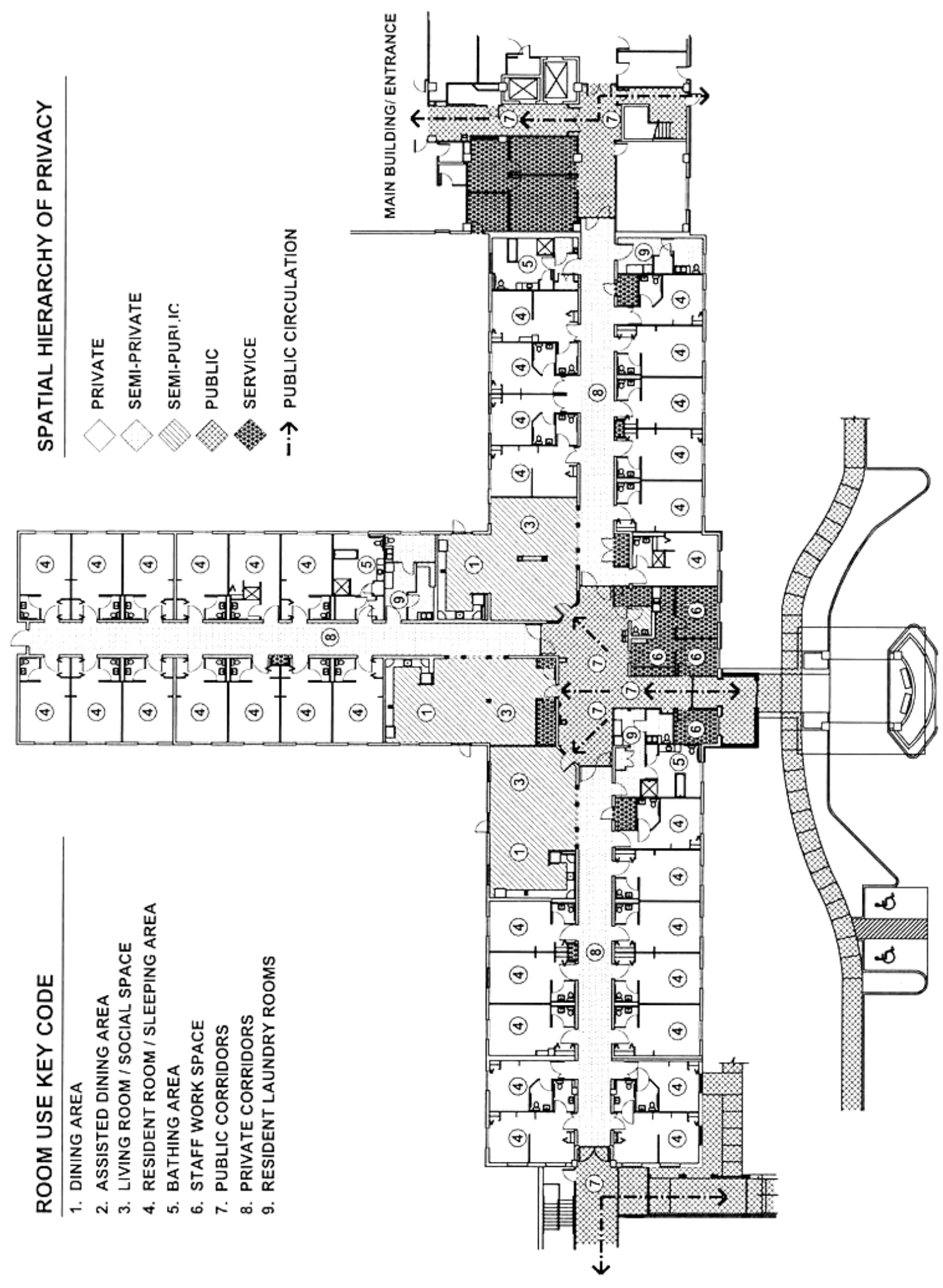

Figure No. 3 - Meadowlark Hills "Household Plan after Remodel:

3 Distinct Households 


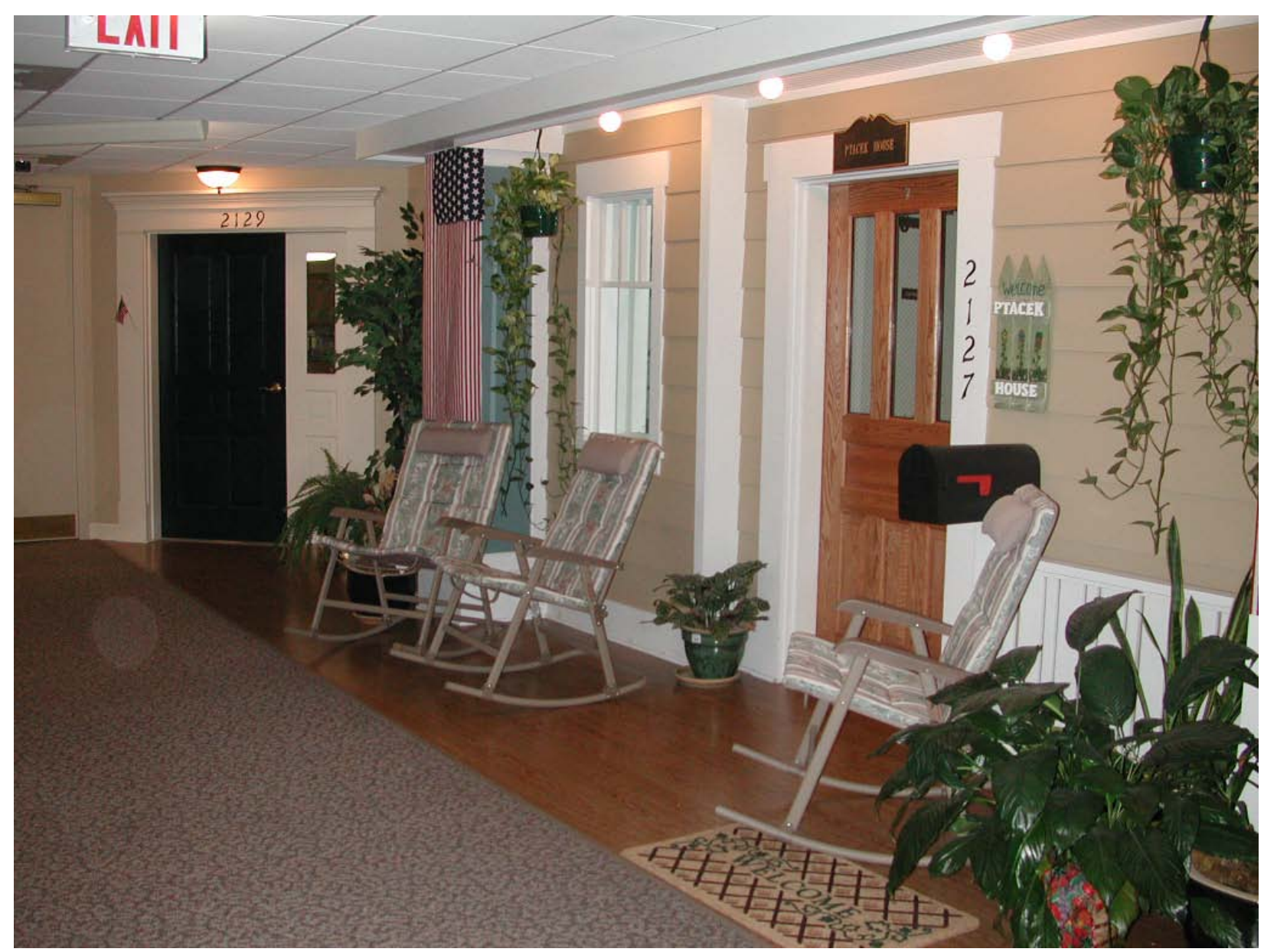

Figure No. 4 - Front Porch Area with Unique Front Doors at Individual Households 